\title{
Mandibular Anterior Ridge Augmentation Using Chin Graft: A Clinical Report
}

\author{
Khoshhal S1, Hedayatipanah $\mathbf{M}^{2^{*}}$, Vafaee $\mathrm{F}^{3}$, Torabi $\mathbf{S}^{4}$ \\ 1Dental Implants Research Center, \\ Periodontics Department, Hamadan University of Medical Sciences, Hamadan, Iran. \\ ${ }^{2}$ Assistant professor, \\ Periodontics department, Faculty of dentistry, Hamadan University of Medical Sciences, Hamadan, Iran. \\ ${ }^{3}$ Associate Professor, Dental Implants Research Center, \\ Prosthodontics Department, Hamadan University Of Medical Sciences, Hamadan, Iran. \\ ${ }^{4}$ Department of Periodontics, Faculty of dentistry, Zanjan University of Medical Sciences, Zanjan, Iran.
}

\begin{abstract}
Insufficient bone volume is a serious challenge for implant placement in correct position to provide the biomechanical, functional and esthetical considerations needs of a prosthesis. Bone grafting is often necessary to place the implant in the proper location for an ideal esthetic result.

This case report addresses surgical procedure for ridge augmentation using chin graft in mandibular anterior region. At first the ridge was knife edge and the bone volume was insufficient. Six month after Autologous bone block augmentation, CBCT was shown increasing in ridge width significantly, that it was suitable for implant placement.

Intraoral bone grafts is a reliable surgical technique for obtaining sufficient bone volume. Cortical bone grafts maintain their features significantly better than cancellous bone grafts. The use of membrane and bone particle can decrease the amount of resorption but soft tissue management should be considered.
\end{abstract}

\section{INTRODUCTION}

Occlusion reconstruction with dental implants is an efficient treatment in edentulous patients who interested in treatment with better esthetic results. ${ }^{1}$ One of the most common problem is an insufficient bone volume that is occur due to periodontal disease, trauma and long-lasting tooth extraction. 2,3 In this situation implant placement in correct position for biomechanical, functional and esthetical considerations needs of a prosthesis is impossible. In addition sufficient bone volume is needed for ensuring long-lasting implant stability. ${ }^{4}$ Therefore correction of bone deficiencies with ridge augmentation allows ideal implant placement and creates a natural soft tissue profile that can effect on esthetic results. ${ }^{3,5}$ If inadequate bone exists, several surgical techniques may be used to reconstruct the deficient ridge for implant placement.

There are different surgical techniques for lateral augmentation such as: Guided Bone Regeneration ${ }^{6}$, ridge expansion and splitting 7,8 , Autogenous bone graft and horizontal distraction osteogenesis. $^{9}$
Keywords: Ridge Augmentation, Autologous Bone Block, Symphysis Bone Block, Implant.

\section{*Correspondence to:}

Morad hedayatipanah,

Assistant Professor,

Periodontics Department, Faculty of Dentistry,

Hamadan University of Medical Sciences, Hamadan, Iran

\section{Article History:}

Received: 21-10-2016, Revised: 16-11-2016, Accepted: 29-11-2016

\begin{tabular}{|l|r|}
\hline \multicolumn{2}{|c|}{ Access this article online } \\
\hline Website: & Quick Response code \\
www.ijmrp.com & \\
\hline DOI: & \\
10.21276/ijmrp.2016.2.6.031 & \\
\hline
\end{tabular}

The number of key factors present and the geometry of a bony defect are important considerations in the selection of a modality for ridge augmentation. The fewer the number of remaining bony walls, the greater the need for osteopromotive techniques. Although allografts and guided bone regeneration techniques have been used predictably in slight-to-moderate bone regeneration (primarily for inadequate width), these methods have limitations and have been found to produce less favorable results in the treatment of larger bone deficiencies.

Autologous cortical/trabecular bone grafts may be considered the gold standard in the repair of moderate to severe alveolar atrophy and bone defects. The use of particulate autogenous with barrier membranes is an effective method for reconstructing deficiencies in small edentulous segments, ${ }^{10}$ but the results of this method be more controversial in reconstructing larger deficiencies. ${ }^{11,12}$

The use of autogenous bone blocks is efficient in edentulous or partially edentulous patients. 
For partially edentulous patients; extra oral autogenous bone blocks such as iliac or calvarial due to higher costs, alteration of ambulation, and the need for hospitalization and general anesthesia, do not accepted easily for ridge augmentation. Indeed the use bone grafting is an aggressive method for ridge augmentation in partially edentulous patients. ${ }^{13,14}$

Among the different bone material, autogenous bone is the best because of its osteogenesis, osteoinductive and osteoconductive property. Intra oral autogenous bone resources are tooth loss space, maxillary tuberosity, mandibular ramus, Symphysis and extraction sockets. Mandibular ramus or symphysis is used when a larger bone volume is needed. ${ }^{15}$

However there are some complications for patients in using autogenous bone block such as: patient's unpleasant feeling, considerable graft resorption, graft exposure. Another complication in symphysis block is nerve injury or in some cases facial profile change may be occurs. ${ }^{3}$ Although autogenous bone block is gold standard in ridge augmentation yet.5,15,16

So the aim of this case report is to evaluate the clinical and radiographic measurement; in order to assess bone volume gain after symphysis bone block placement in partially edentulous patient.

\section{CASE PRESENTATION}

The patient was a 28-year-old male. His chief complaint was missing teeth in mandibular anterior region. He requested fix prosthesis, preferably an implant supported. He didn't have any systemic problem. In extra oral and intra oral examination all findings were normal. For evaluating bone quantity and quality CBCT was requested. CBCT demonstrated insufficient bone volume in anterior region, especially in the space of teeth number 23 and 24 that the ridge was knife edge (Fig 1). We had different treatment options such as mini implant placement; ridge expansion and bone block graft. We could not use mini implant because of insufficient ridge width and long span region. Also we couldn't expand the ridge properly. So we chose autogenous bone block for ridge augmentation and because of the anterior region, the use of symphysis block was logical. Symphysis dimention was controlled by CBCT (Fig 2). After patient preparation infiltrated local anesthesia was injected. We used 4 lidocaine \%2 (1:100,000 epinephrine) carpules. Remote incision was made and full thickness mucoperiosteal flaps were raised on the buccal and lingual aspects but on the lingual aspect minimal tissue reflection was performed in order to preserve the periosteum attachment and it would be repositioned easily with good healing. But on the buccal aspect more reflection is needed to have enough bone access. 4 bone blocks within $8 \mathrm{~mm}$ diameter and $4.5 \mathrm{~mm}$ width were removed using medium size trephine drill (Fig 3). Blocks were fixed by screw coronal and apically on both sides of midline in the lateral teeth position (Fig 4). We used allograft particulate (FDBA 70\% - DFDBA 30\%) (CenoBone, Tissue Regeneration Corporation, Kish, Iran) for filling interblocks space and covered the whole region with collagen membrane $(30 \times 30 \mathrm{~mm})$ (Cerabone, Botiss Biomaterial, Germany). Then; tension free mucoperosteal tissue closure; was performed by parallel incisions to the crestal incision would then be made through the periosteum of the facial flap. This procedure does allow the facial flap to advance several millimeters over the membrane using silk 3-0 nonresorbable suture (SUPASIL, Supa medical devices, Tehran, Iran). Amoxicillin $500 \mathrm{mg}$, non-steroidal analgesics (lbuprofen $400 \mathrm{mg}$ ) and $0.2 \%$ chlorhexidine (CHX) mouth rinse were administered. Sutured removed after two weeks. Unfortunately; one week after the surgery the membrane exposure was observed. We emphasis, the patient flushing the exposure site with $0.2 \%$ chlorhexidine mouth rinse two wise per day for four weeks.

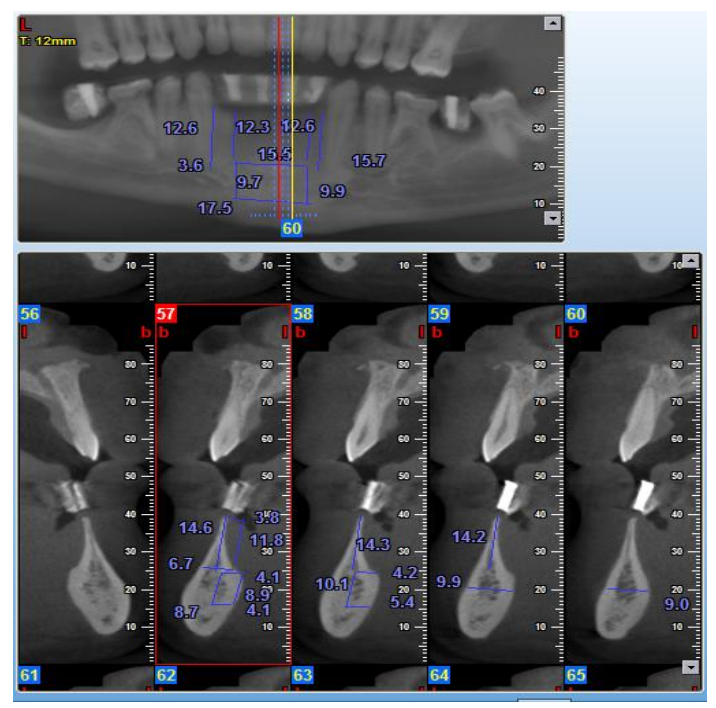

Fig1: Insufficient bone volume
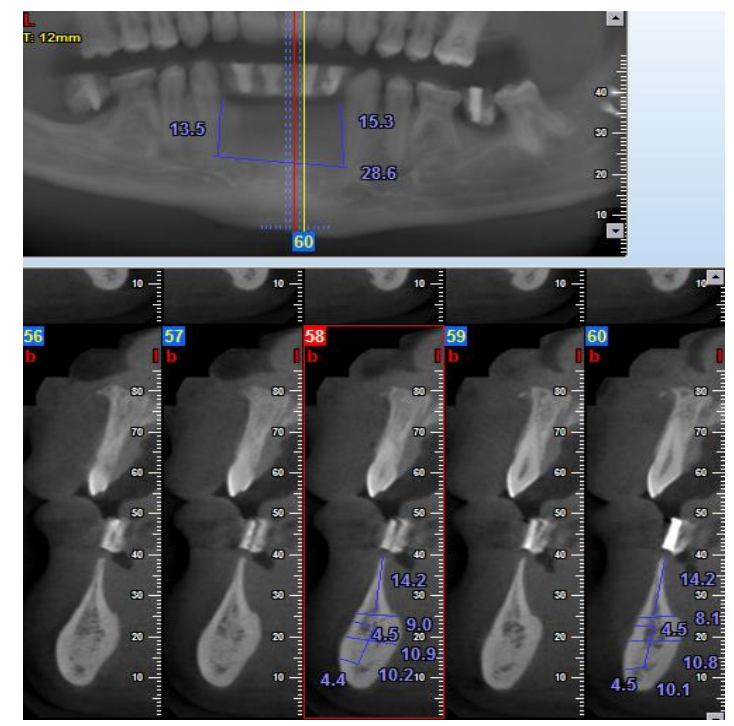

Fig 2: Symphysis dimension

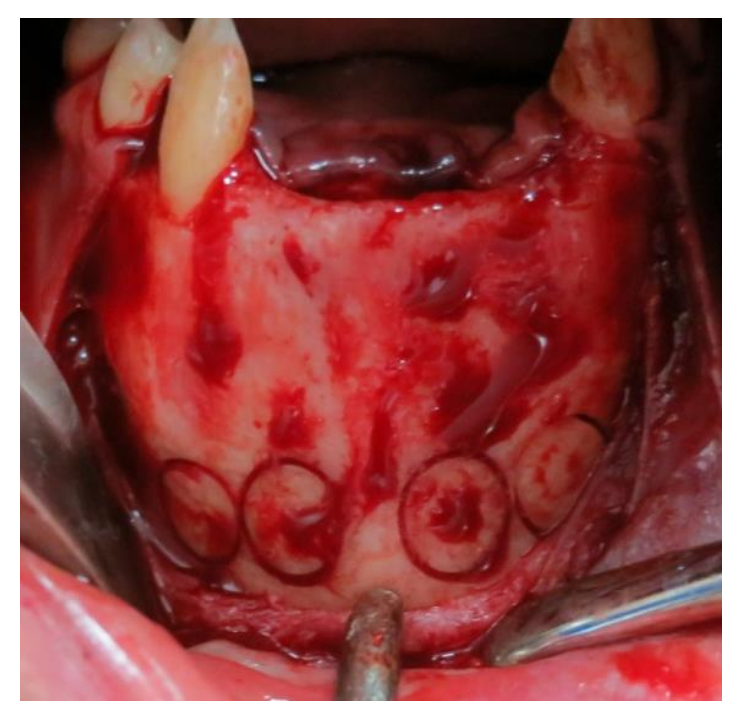

Fig 3: Block dimension 

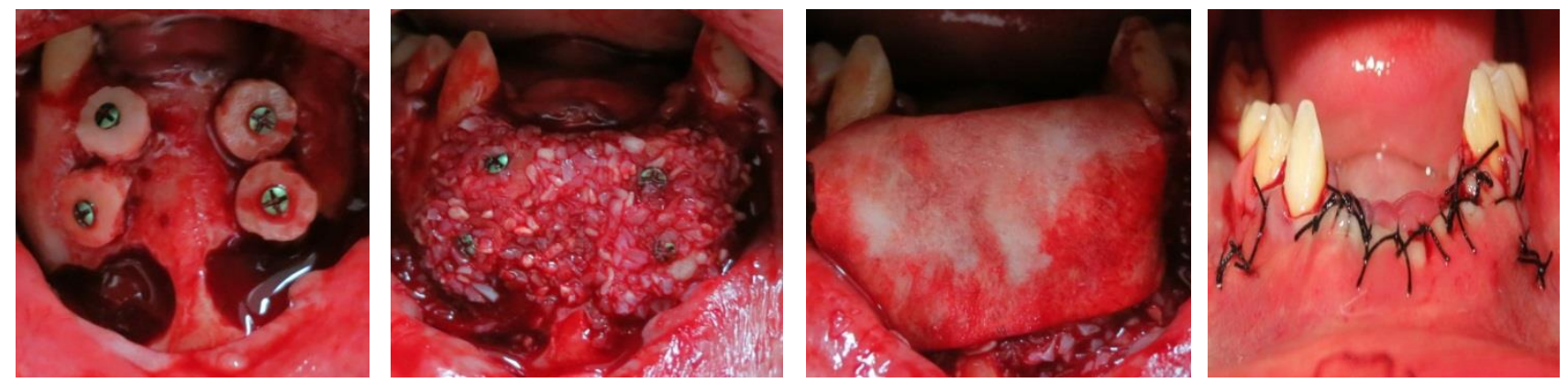

Fig 4: Block fixation
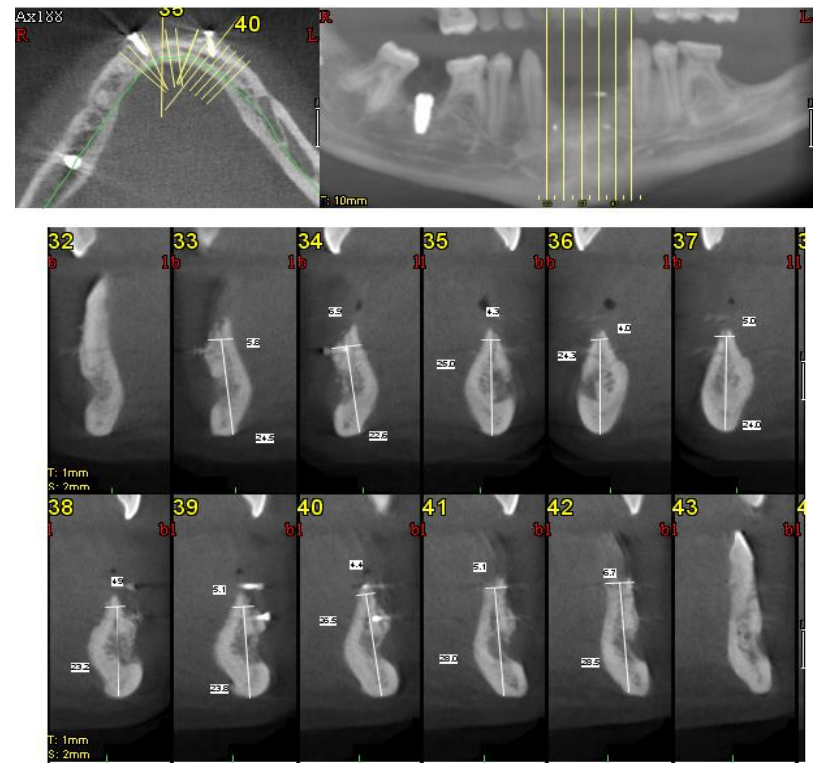

Fig 5: 6 month after autogenous bone graft

The wound dehiscence is allowed to heal by secondary intention after 4 weeks. But after this times increased the wound dehiscence and the upper right block was mobiles. At this time, we attempt to soft tissue flap to recover the graft by High-Density Polytetrafluoroethylene membrane (dPTFE) (Osteogenics, Biomedical) after the de- epithelialization around the mobile block, decortication and fixation the bone block that a small site of the membrane was exposed (so it wouldn't be contaminated if it is exposed). We prescribed the flushing of site with $0.2 \%$ chlorhexidine mouth rinse. One month later membrane and upper right block exposure was incrementally increased that tougher with increased mobility. However we had to remove one of the blocks (upper right one) and non-resorb able membrane. Allowed to heal by secondary intention. After 6 month we requested CBCT again to evaluate the amount of bone gain. CBCT analysis displayed enough bone volume for implant placement and ridge width increased obviously (Fig 5). The amount of horizontal bone gain in the left lateral incisor site was $2.5 \mathrm{~mm}$, but in the $4 \mathrm{~mm}$ apically from the marginal bone of right incisor site was $3.5 \mathrm{~mm}$, because the upper right bone block was failed. This report demonstrated the successful use of bone autologous block for ridge augmentation.

\section{DISCUSSION}

Intra oral only grafts are a reliable surgical technique for obtaining sufficient bone volume for implant placement. Soft tissue management is an important part of the procedure. According to
Hiatt and Schallhorn minimum thickness of $1.5 \mathrm{~mm}$ is needed for successful coverage..$^{16}$ The most common host site complication is graft dehiscence and incision line opening. If graft dehiscence occurs, the wound is allowed to heal by secondary intention after 2 to 4 weeks. The block graft may then be recontoured with a diamond bur to reduce the bulk of exposed bone; the bone above the margins of the tissue is ground off. This procedure is repeated every 2 to 4 weeks until the site is closed. No attempt should be made to advance a soft tissue flap to recover the graft for at least 6 to 8 weeks. If the graft becomes mobile, the mobile piece of bone should be removed. ${ }^{17}$

In most cases after using $\mathrm{CHX}$ three times per day for 10 days or removing a part of the graft with a bur the problem is dissolving..$^{18}$ But if the exposure increased we may have to remove graft completely. 3,19 In our case we removed a part of the graft and will augment with allograft particle after implant placement if needed.

Therefore the larger bone block needed to be harvesting with due attention to the amount of bone resorption, ${ }^{3,20}$ Antoun et al. revealed the amount of resorption in cases with using membrane, significantly lower than cases without membrane use $(2.3 \mathrm{~mm}$ versus $0.3 \mathrm{~mm}$ ). ${ }^{21}$ Due to the complexity of clinical handling of soft tissue when using non-resorbable membranes some author prefer to use resorbable membrane.

In our case, we used collagen membrane at first and after its exposure we use dPTFE membrane to overcome the possibility of its exposure.

According to Maiorana et al. the use of bovine bone particles for protecting block grafts, decrease the amount of resorption (18.3\% in control group versus $9.3 \%$ in test group). ${ }^{22}$ In our case we used allograft particulate (FDBA $70 \%$ and DFDBA $30 \%$ ). Another complication that was mentioned after chin graft, is temporary paresthesia that was occurred $10 \%$ to $50 \% .{ }^{23}$ Fortunately; it didn't occur in our case. Phillips et al revealed that membranous bone like mandible undergoes less resorption than endocondral bone such as iliac crest. ${ }^{24}$ If the graft volume that is needed doesn't so much, mandibular bone is the best choice..$^{17,25}$ Clinical data shows that mandibular block grafts are safe, effective and simple method for ridge augmentation in partially edentulous patients. ${ }^{4}$ Therefore in these cases intraoral bone resources are better and accompany with lower complications. ${ }^{26}$

Bone block harvested from the symphysis is corticocancellous in nature and have cortical structures. According to Kim et al cortical bone grafts maintain their features significantly better than cancellous bone grafts. ${ }^{27}$

According to recent systematic review there is no difference in survival rates between placing implants in bone block or guided bone regeneration or native bone. ${ }^{3}$ 


\section{REFERENCES}

1. Zahrani AA. Augmentation in two stages of atrophic alveolar bone prior to dental rehabilitation: a case report. J Contemp Dent Pract. 2007;8(6):57-63.

2. Massoumeh Khoshhal PT, Fariborz Vafaee, Shilan Razaghi. . Mandibular ridge splitting and gradual bone expantion technique for immediate placement of implant in the posterior thin region. $A$ clinical report. Avicenna J Dent Res. 2013;5(2):e19463.

3. Aloy-Prosper A, Penarrocha-Oltra D, Penarrocha-Diago M, Penarrocha-Diago M. The outcome of intraoral onlay block bone grafts on alveolar ridge augmentations: a systematic review. Med Oral Patol Oral Cir Bucal. 2015;20(2):e251-8.

4. Cordaro L, Amade DS, Cordaro M. Clinical results of alveolar ridge augmentation with mandibular block bone grafts in partially edentulous patients prior to implant placement. Clin Oral Implants Res. 2002;13(1):103-11.

5. Sanz-Sanchez I, Ortiz-Vigon A, Sanz-Martin I, Figuero E, Sanz M. Effectiveness of Lateral Bone Augmentation on the Alveolar Crest Dimension: A Systematic Review and Meta-analysis. J Dent Res. 2015;94(9 Suppl):27.

6. Bedrossian E, Tawfilis A, Alijanian A. Veneer grafting: a technique for augmentation of the resorbed alveolus prior to implant placement. A clinical report. Int J Oral Maxillofac Implants. 2000;15(6):853-8.

7. Summers RB. The osteotome technique: Part 2--The ridge expansion osteotomy (REO) procedure. Compendium. 1994;15(4):436.

8. Sethi A, Kaus T. Maxillary ridge expansion with simultaneous implant placement: 5-year results of an ongoing clinical study. Int J Oral Maxillofac Implants. 2000;15(4):491-9.

9. Takahashi T, Funaki K, Shintani H, Haruoka T. Use of horizontal alveolar distraction osteogenesis for implant placement in a narrow alveolar ridge: a case report. Int $\mathrm{J}$ Oral Maxillofac Implants. 2004;19(2):291-4.

10. Fugazzotto PA. Success and failure rates of osseointegrated implants in function in regenerated bone for 6 to 51 months: a preliminary report. Int J Oral Maxillofac Implants. 1997;12(1):1724.

11. Lang NP, Hammerle CH, Bragger U, Lehmann B, Nyman SR. Guided tissue regeneration in jawbone defects prior to implant placement. Clin Oral Implants Res. 1994;5(2):92-7.

12. Chiapasco M, Abati S, Romeo E, Vogel G. Clinical outcome of autogenous bone blocks or guided bone regeneration with ePTFE membranes for the reconstruction of narrow edentulous ridges. Clin Oral Implants Res. 1999;10(4):278-88.

13. Keller EE, Van Roekel NB, Desjardins RP, Tolman DE. Prosthetic-surgical reconstruction of the severely resorbed maxilla with iliac bone grafting and tissue-integrated prostheses. Int J Oral Maxillofac Implants. 1987;2(3):155-65.

14. Isaksson S, Alberius P. Maxillary alveolar ridge augmentation with onlay bone-grafts and immediate endosseous implants. J Craniomaxillofac Surg. 1992;20(1):2-7.

15. Yavuz MS, Buyukkurt MC, Tozoglu S, Dagsuyu IM, Kantarci M. Evaluation of volumetry and density of mandibular symphysis bone grafts by three-dimensional computed tomography. Dent Traumatol. 2009;25(5):475-9.

16. Hiatt WH SR. Intraoral transplants of cancellous bone and marrow in periodontal lesions. J Periodontol. 1973;44(4):194-208.
17. Misch CM. Comparison of intraoral donor sites for onlay grafting prior to implant placement. Int J Oral Maxillofac Implants. 1997;12(6):767-76.

18. Cordaro L, Torsello F, Morcavallo S, di Torresanto VM. Effect of bovine bone and collagen membranes on healing of mandibular bone blocks: a prospective randomized controlled study. Clin Oral Implants Res. 2011;22(10):1145-50.

19. Penarrocha-Diago M, Aloy-Prosper A, Penarrocha-Oltra D, Guirado JL, Penarrocha-Diago M. Localized lateral alveolar ridge augmentation with block bone grafts: simultaneous versus delayed implant placement: a clinical and radiographic retrospective study. Int $\mathrm{J}$ Oral Maxillofac Implants. 2013;28(3):846-53.

20. Chiapasco M, Zaniboni M, Boisco M. Augmentation procedures for the rehabilitation of deficient edentulous ridges with oral implants. Clin Oral Implants Res. 2006;2:136-59.

21. Antoun H, Sitbon JM, Martinez H, Missika P. A prospective randomized study comparing two techniques of bone augmentation: onlay graft alone or associated with a membrane. Clin Oral Implants Res. 2001;12(6):632-9.

22. Maiorana C, Beretta M, Salina S, Santoro F. Reduction of autogenous bone graft resorption by means of bio-oss coverage: a prospective study. Int $\mathrm{J}$ Periodontics Restorative Dent. 2005;25(1):19-25.

23. Clavero J, Lundgren S. Ramus or chin grafts for maxillary sinus inlay and local onlay augmentation: comparison of donor site morbidity and complications. Clin Implant Dent Relat Res. 2003;5(3):154-60.

24. Phillips JH, Rahn BA. Fixation effects on membranous and endochondral onlay bone graft revascularization and bone deposition. Plast Reconstr Surg. 1990;85(6):891-7.

25. Restoy-Lozano A, Dominguez-Mompell JL, Infante-Cossio P, Lara-Chao J, Espin-Galvez F, Lopez-Pizarro V. Reconstruction of mandibular vertical defects for dental implants with autogenous bone block grafts using a tunnel approach: clinical study of 50 cases. Int J Oral Maxillofac Surg. 2015;44(11):1416-22.

26. Gungormus M, Yilmaz AB, Ertas U, Akgul HM, Yavuz MS, Harorli A. Evaluation of the mandible as an alternative autogenous bone source for oral and maxillofacial reconstruction. J Int Med Res. 2002;30(3):260-4.

27. Kim JH KJ, Park KK. Biologic factors influencing the fate of onlay bone graft on the craniofacial skeleton. . J Korean Soc Plast Reconstr Surg. 1998;25:557-65.

\section{Source of Support: Nil. Conflict of Interest: None Declared.}

Copyright: (c) the author(s) and publisher. IJMRP is an official publication of Ibn Sina Academy of Medieval Medicine \& Sciences, registered in 2001 under Indian Trusts Act, 1882.

This is an open access article distributed under the terms of the Creative Commons Attribution Non-commercial License, which permits unrestricted non-commercial use, distribution, and reproduction in any medium, provided the original work is properly cited.

Cite this article as: Khoshhal S, Hedayatipanah M, Vafaee F, Torabi S. Mandibular Anterior Ridge Augmentation Using Chin Graft: A Clinical Report. Int J Med Res Prof. 2016; 2(6):154-57. DOI:10.21276/ijmrp.2016.2.6.031 